\title{
A test of the assumed nature of the dual codes
}

\author{
MICHELE S. MONDANI \\ University of Oklahoma, Norman, Oklahoma 73019
}

\begin{abstract}
Subjects learned either an abstract or concrete paired-associate list and were required to produce either a sentence or a drawing to each pair during study trials. A within-subjects variable of lists, mixed with respect to double-function or single-function items, tested Paivio's (1971) directionality hypothesis and his assumptions concerning the nature of the dual codes. The results indicated support for Paivio's hypotheses when only the imagery value of the pairs was considered. When type of code actually used by the subjects was considered, however, the results were completely contrary to Paivio's hypotheses. The latter effect cannot be reconciled with the assumed parallel vs sequential distinction between the dual codes. Alternative interpretations were offered.
\end{abstract}

Paivio (1971) proposed that the superiority of concrete over abstract items in most learning tasks is due to the availability of dual codes (imaginal and verbal) for conrete items, whereas only a single (verbal) code is available for abstract items. The strength of Paivio's assumptions concerning the parallel vs sequential nature of the two codes is implicit in his directionality hypothesis, which states that forward and backward associations are equivalent for imaginally processed pairs, whereas forward associations are superior for verbally processed pairs. This directionality hypothesis has found both support (Mondani \& Battig, 1973; Smythe, 1970) and nonsupport (Wollen \& Lowry, 1971).

The present study provides an extension and further test of Paivio's (1971) directionality hypothesis and, consequently, of the assumptions concerning the nature of the two postulated codes. The variables of interest involve a between-subjects variable of concrete-concrete and abstract-abstract word pairs and a within-subjects variable of single-function and double-function items. In the double-function pairs, errors may be made either by not retrieving the correct response ("other" errors) or by retrieving the item which would have been appropriate in the backward direction ("backward" errors). The latter type of errors should predominate in conditions where subjects could not distinguish between the

This research was based on a PhD dissertation submitted by the author to the Graduate School of the University of Colorado and was conducted at the Institute for the Study of Intellectual Behavior. The author wishes to express her appreciation to William F. Battig for his encouragement and assistance throughout this project, and to the other members of the committee, Bruce R. Ekstrand, Gregory A. Kimble, and Edward J. Crothers for their helpful comments. The research reported here was supported by Grant GB34077X from the National Science Foundation. The author also wishes to thank N. Jack Kanak for his helpful comments during the preparation of this manuscript. William F. Battig sponsors this paper and takes full editorial responsibility for its content. Requests for reprints should be sent to Michele S. Mondani, Department of Psychology, University of Oklahoma, Norman, Oklahoma 73019. forward and backward directions. According to the Paivio hypothesis, such conditions should exist for concrete or imaginally encoded pairs. With abstract or verbally encoded pairs, however, the forward-backward discrimination should be much easier, thus resulting in fewer such directional errors.

The present experiment included an assessment of whether the subjects were using verbal or imaginal mediators. Typically, there are problems in making explicit such implicit strategies. Some investigators (e.g., Martin, Boersma, \& Cox, 1965) have questioned subjects at the conclusion of list learning: Others (e.g., Epstein, Rock, \& Zuckerman, 1960; Paivio, Smythe, \& Yuille, 1968) have manipulated the materials along the concreteness dimension to enhance the use of particular mediators. A third technique has been to instruct subjects as to mediator usage (e.g., Bower \& Winzenz, 1970). Sometimes combinations of these techniques have been employed (e.g., Wollen \& Lowry, 1971). There are obvious problems with each of these techniques, as evidence by the difficulty Paivio (Paivio \& Yuille, 1967; Yuille \& Paivio, 1968) had in testing the predicted interaction between concreteness of stimulus material and imaginal vs verbal mediator instructions. This difficulty led Paivio and Foth (1970) to use a forced production technique requiring the subject to actually draw a picture for the imaginal mediators and write a sentence for the verbal mediators. Although they used the technique to confirm that their subjects were actually adhering to the instructed strategy, the present experiment employed the Paivio and Foth technique to assess whether the subject was using a verbal or imaginal mediator.

\section{METHOD}

\section{Subjects and Design}

The complete factorial design was directed at the shifting of mediators across learning trials, including three between-subjects variables of learning instructions (incidental or intentional), task requirements in terms of mediator production (free, stay, 
or shift), and imagery value of the words (abstract or concrete), as well as a within-subjects variable of double-function and single-function items. Only the imagery and functionality variables are of interest in the present report. Collapsing across all other between-subjects variables, there were 60 subjects who were presented with the concrete and 60 subjects who were presented with the abstract lists. An additional group of 20 control subjects, used to determine the effects of forced mediator production, is omitted from the present discussion since the subjects lacked the required mediator data.

\section{Materials and Procedure \\ Thirty concrete [imagery $(I)=6.32$, concreteness $(C)=6.68$ ] and 30 abstract $(I=3.24, C=2.54)$ words were selected from the Paivio, Yuille, and Madigan (1968) norms and were then equated for meaningfulness and word length. From these words, two 20-item concrete and two 20-item abstract lists were formed. All pairings were made so as to maximize the availability of both types of mediators. Prior to data collection, the adequacy of such pairings was tested on 16 independent subjects, who demonstrated that both drawings and sentences could be produced for every pair. Each list contained 10 single- function and 10 double-function pairs. \\ The word pairs were typed in capital letters on $3 \times 5$ in. cards and were presented in succession for 15 sec each. On every trial the subjects were provided with booklets of 20 blank sheets, and produced their sentence or drawing for each pair on a dif- ferent sheet. A latency measure used to indicate the accessi- bility of a given mediator was taken from the time the pair was presented to the time the subject began mediator production. The subjects were required to produce sentences and/or drawings on every study trial. Each subject was first presented with two consecutive study trials, followed by a written cued recall test with the stimulus word presented, and then a recognition test. Finally, a third study trial was given, followed by another recall-recognition testing sequence. Since only recall errors are crucial for the present report, presentation of the recognition test data will be omitted.}

\section{RESULTS AND DISCUSSION}

Performance on the recall tests was measured in terms of total errors or failures to give the correct response, along with two partitionings of these total errors. The first partitioning was based on item type (number of errors for the double-function items vs number of errors for the single-function items). The second partitioning was based on error type-"other" errors (where the subject failed to provide an appropriate response to either a double- or a single-function item) and "backward" errors (where the subject responded to a double-function item with a response which would have been appropriate in the backward direction).

For the analyses on both recall tests, Table 1 shows that performance on concrete pairs was markedly superior to performance on abstract pairs $[F(1,112)=$ $30.07,17.34, \mathrm{p}<.01$ ]. Table 1 also shows more "backward" and fewer "other" errors for concrete than for abstract pairs, as predicted by Paivio (1971). The resulting interaction of concrete-abstract with error type was highly significant on both recall tests $[F(1,112)=$ $30.73,20.20, p<.01]$. When the total errors were partitioned into double- and single-function items, significantly more errors were committed on the double-
Table 1

Mean Other (0) and Backward (B) Errors for Concrete and Abstract Pairs on First and Second Recall Tests

\begin{tabular}{lccccccc}
\hline & \multicolumn{3}{c}{ Concrete } & & \multicolumn{3}{c}{ Abstract } \\
\cline { 2 - 5 } \cline { 6 - 8 } & O & B & Total & & O & B & Total \\
\hline Recall 1 & 2.63 & 4.05 & 6.68 & & 6.58 & 3.25 & 9.83 \\
Recall 2 & 1.02 & 4.33 & 5.35 & & 3.60 & 3.95 & 7.55 \\
Total & 3.65 & 8.38 & 12.03 & & 10.18 & 7.20 & 17.38 \\
\hline
\end{tabular}

function items $[F(1,112)=312.54,510.84, p<.01]$, but there was no interaction with imagery. Thus, the double-function items were equally difficult for both the abstract and concrete pairs, and the results presented in Table 1 are not an artifact of differential difficulty of the item types.

Thus far, the predictions stemming from Paivio's (1971) directionality hypothesis are confirmed. The directionality hypothesis, however, was based upon the proposed processing differences between concrete and abstract pairs. The present study, which required production of sentences and drawings, provides some direct tests of such processing notions. Specifically, because of differential availability of verbal and pictorial mediators, there should be a larger difference between the latency to begin production of a drawing than to begin production of a sentence for abstract as opposed to concrete pairs. Although not significant, there was a trend in this direction. Likewise, more drawings should have been produced for concrete as opposed to abstract pairs. Again the trend was in the appropriate direction but was far from significant.

The present results thus support Paivio's directionality hypothesis with the significant interaction of error type with concreteness level shown in Table 1 , while the prerequisite dual-coding assumptions receive only limited support from the latency data and slightly more drawings for concrete pairs. However, all of these manipulations were based on the item attributes (abstract vs concrete) rather than on the encoding attributes (verbal vs imaginal). A far more direct test of the proposed processing differences can be obtained with the examination of the interaction of error type by mediator type (sentence vs drawing). To compare differences in recall performance for pairs with drawing and sentence mediators, the proportion of mediators of each type which led to recall errors was calculated separately for "other" and "backward" errors on the second recall test.

The means of Table 2 indicate a highly significant interaction of "other" and "backward" errors with sentences and drawings $[F(1,96)=12.16, p<.01]$. This interaction, however, is completely contrary to that predicted from the Paivio (1971) hypothesis. That is, there is virtually no difference in the proportion of "other" and "backward" errors with the imaginal mediators, whereas there are many more "backward" 
Table 2

Mean Proportion of Backward and Other Errors for Imaginal and Verbal Mediators

\begin{tabular}{lll}
\hline & $\mathrm{O}$ & $\mathrm{B}$ \\
\hline Drawings & .08 & .11 \\
Sentences & .12 & .23 \\
\hline
\end{tabular}

errors with verbal mediators. Thus, the facilitation of drawings over sentences was greatest in terms of "backward" errors. When one group of 40 subjects was analyzed separately, not only did this same highly significant interaction emerge, but an additional interaction of these two variables with imagery $[F(1,32)=$ $4.18, \mathrm{p}<.05]$ indicated the effect was located entirely within the concrete pairs.

The finding that drawings lead to better performance in terms of "backward" errors, especially for concrete pairs, is completely contrary to Paivio's (1971) postulated processing differences between concrete and abstract words. Thus, while the results do yield confirmation of predictions in terms of item attributes (i.e., imagery value of the words), they do not support Paivio's predictions in terms of processing differences. It should be noted, however, that Paivio's theory does not deal explicitly with the present double-function items.

Drawings were highly effective, especially in reducing "backward" errors. Drawings, in general, may have greater specificity as mediators, which may have led to enhanced performance. On the other hand, something in the nature of the drawings per se could have reduced "backward" errors. Regardless of the underlying mechanism, it seems unusual that drawings were used so infrequently for double-function items. The subjects may have tended not to draw to items they felt could be confused easily, or they may have decided not to draw to items whose pictorial referents might be confused with those of another item. Thus, subjects may well have been capable of producing drawings that were effective in eliminating "backward" errors, but they refrained from doing so.

\section{REFERENCES}

Bower, G. H., \& Winzenz, D. Comparison of associative learning strategies. Psychonomic Science, 1970, 20, 119-120.

Epstein, W., Rock, I., \& Zuckerman, C. B. Meaning and familiarity in associative learning. Psychological Monographs, 1960, 74(Whole No. 491).

Martin, C. J., Boersma, F. J., \& Cox, D. L. A classification of associative strategies in paired-associate learning. Psychonomic Science, 1965, 3, 455-456.

Mondani, M. S., \& Battig, W. F. The role of imagery in paired associate learning. Journal of Verbal Learning and Verbal Behavior, 1973, 12, 401-408.

Paivio, A. Imagery and verbal processes. New York: Holt, 1971.

PaIvio, A., \& Forr, D. Imaginal and verbal mediations and noun concreteness in paired-associate learning: The elusive interaction. Journal of Verbal Learning and Verbal Behavior, 1970, 9, 384-390.

Paivio, A., Smythe, P. C., \& Yuille, J. C. Imagery versus meaningfulness of nouns in paired-associate learning. Canadian Journal of Psychology, 1968, 22, 427-441.

Parvio, A., \& Yurlle, J. C. Mediation instructions and word attributes in paired-associate learning. Psychonomic Science, 1967, 8, 65-66.

Paivio, A., Yuille, J. C., \& Madigan, S. Concreteness, imagery, and meaningfulness values for 925 nouns. Journal of Experimental Psychology Monograph Supplement, 1968, 76(1, Part 2).

SMYThe, P. C. Pair concreteness and mediation instruction in forward and backward paired-associate recall. Unpublished doctoral thesis, University of Western Ontario, 1970.

Wollen, K. A., \& LowRY, D. H. Effects of imagery on paired-associate learning. Journal of Verbal Learning and Verbal Behavior, 1971, 10, 276-284.

Yuille, J. C., \& PAIvio, A. Imagery and verbal mediation instructions in paired-associate learning. Journal of Experimental Psychology, 1968, 78, 436-441.

(Received for publication November 1, 1976.) 